\title{
Group I Metabotropic Glutamate Receptors Elicit Epileptiform Discharges in the Hippocampus through PLC $\beta 1$ Signaling
}

\author{
Shih-Chieh Chuang, ${ }^{1}$ Riccardo Bianchi, ${ }^{1}$ Daesoo Kim, ${ }^{2}$ Hee-Sup Shin, ${ }^{2}$ and Robert K. S. Wong ${ }^{1}$ \\ ${ }^{1}$ Department of Physiology and Pharmacology, State University of New York-Health Science Center at Brooklyn, \\ Brooklyn, New York 11203, and 2National CRI Center for Calcium and Learning, Department of Life Science, Pohang \\ University of Science and Technology, Pohang, 790-784, Korea
}

\begin{abstract}
Activation of metabotropic glutamate receptors (mGluRs) produces multiple effects in cortical neurons, resulting in the emergence of network activities including epileptiform discharges. The cellular mechanisms underlying such network responses are largely unknown. We examined the properties of group I mGluR-mediated cellular responses in CA3 neurons and attempted to determine their role in the generation of the network activities. Group I mGluR stimulation causes depolarization of hippocampal neurons. This depolarization is primarily mediated by two sets of conductance change: the opening of a voltagedependent cationic conductance (mediating $I_{\text {mGluR(v) }}$ ) and the closing of a voltage-independent (background) $\mathrm{K}^{+}$conductance. $I_{\text {mGluR(v) }}$ was no longer elicited by group I mGluR agonists in the presence of U73122, a phospholipase C (PLC) blocker. Also, the current could not be activated in hippocampal CA3 neurons from PLC $\beta 1$ knock-out mice. In contrast, sup-
\end{abstract}

Group I metabotropic glutamate receptor (mGluR) stimulation elicits synchronized oscillations in the hippocampus. The discharges consist of rhythmic episodes of 15-27 Hz oscillations of up to $15 \mathrm{sec}$ in duration and with intervals of up to $10 \mathrm{sec}$. The oscillatory discharges are maintained by cycles of AMPAmediated phasic synaptic depolarizations of pyramidal cells. The pattern of activities is not altered when GABAergic inhibition is blocked (Taylor et al., 1995). Essential features of the oscillation, including its frequency and the synchronous occurrence in all hippocampal neurons (hypersynchrony), allow us to draw a parallel between this event and the ictal discharges accompanying seizure (Wong et al., 1999). At present, the cellular mechanisms underlying the group I mGluR-mediated ictal-like discharges remain unclear. Our hypothesis is that each episode (up to $10 \mathrm{sec}$ ) of $15-27 \mathrm{~Hz}$ oscillations is initiated and sustained by a group I mGluR-mediated depolarization. The depolarization fires the CA3 pyramidal cells and drives the recurrent synapses to bring about the synchronized discharge. To test this hypothesis, we examined the properties of ionic conductances underlying the group I mGluR-mediated depolarizations and evaluated how a

Received March 23, 2001; revised May 21, 2001; accepted May 25, 2001.

This work was supported by National Institute of Neurological Disorders and Stroke Grant NS-35481. We thank Dr. Lisa Merlin for providing helpful input to this manuscript.

Correspondence should be addressed to Robert K. S. Wong, State University of New York-Health Science Center at Brooklyn, Box 29, 450 Clarkson Avenue, Brooklyn, NY 11203. E-mail: bwong@netmail.hscbklyn.edu.

Copyright (C) 2001 Society for Neuroscience $0270-6474 / 01 / 216387-08 \$ 15.00 / 0$ pression of PLC signaling did not affect the group I mGluRmediated suppression of background $\mathrm{K}^{+}$conductance. Thus, the suppression of the background $\mathrm{K}^{+}$conductance occurred upstream to PLC activation, whereas the generation of $I_{\text {mGluR(V) }}$ occurred downstream to PLC activation. Group I mGluR agonists normally elicited rhythmic single cell and population burst responses in the CA3 neurons. In the absence of an ImGluR(V) response, CA3 neurons in slices prepared from PLC $\beta 1-/-$ mutant mice could no longer generate these responses. The results suggest that $I_{\text {mGluR(V) }}$ expression in CA3 hippocampal neuron is PLC $\beta 1$-dependent and that $I_{\text {mGluR(V) }}$ plays a necessary role in the generation of rhythmic single cell bursts and synchronized epileptiform discharges in the CA3 region of the hippocampus.

Key words: PLC $\beta 1$; signal transduction; epileptiform discharges; mGluRs; hippocampus; CA3 population oscillations

selective blockade of a conductance affects the synchronized ictal-like discharges.

Group I mGluRs depolarize pyramidal cells primarily by reducing potassium conductances and by activating inward currents. Three types of inward current that are activated by mGluR agonist in the hippocampal cells have been described. First, mGluR activation elicits a $G$ protein-dependent, voltageindependent nonselective cationic (CAN) current (Guérineau et al., 1994; Pozzo-Miller et al., 1995; Congar et al., 1997). Additional evidence suggests that the CAN current elicited in CA1 cells by group I mGluR agonists is gated by intracellular $\mathrm{Ca}^{2+}$ (Congar et al., 1997). Second, Heuss et al. (1999) described an inward current activated by synaptic or agonist stimulation of group I mGluRs in CA3 cells. The current shows nonlinear voltage dependency with a region of negative-slope conductance at hyperpolarized potentials. Activation of this group I mGluRdependent current is $\mathrm{G}$ protein-independent but requires the activation of an Src-family tyrosine kinase. Third, we observed that stimulation of group I mGluR elicits a voltage-dependent inward current $\left[I_{\mathrm{mGluR}(\mathrm{V})}\right]$ in CA3 pyramidal cells (Chuang et al., 2000). The voltage dependency of $I_{\text {mGluR(V) }}$ can be compared with the $\mathrm{G}$ protein-independent current described by Heuss et al. (1999) but distinguishes it from the CAN current described in the above (Guérineau et al., 1994; Pozzo-Miller et al.,1995; Congar et al., 1997). We continued our studies on $I_{\text {mGluR(V) }}$ by further evaluating its activation threshold and probing the intracellular transduction mechanisms involved in its generation. This information allowed us to assess the involvement of $I_{\text {mGluR(V) }}$ in the generation of the ical-like episodes of $15-27 \mathrm{~Hz}$ oscillations. 


\section{MATERIALS AND METHODS}

Animals. Ten-week-old F1 homozygous and wild-type littermates were obtained from crosses of C57BL/6J(N8)PLC $\beta 1+/+$ and 129S4/ SvJae(N8)PLC+/-. The genotypes were determined by PCR analysis as described previously (Kim et al., 1997). Animal care and handling were performed following institutional guidelines (State University of New York Health Science Center, Brooklyn, NY; Pohang University of Science and Technology, Pohang, Korea). The mice were maintained with ad libitum access to food and water on a $12 \mathrm{hr}$ light/dark cycle with the light cycle beginning at 6:00 A.M.

Slice preparation. Transverse slices (400 $\mu \mathrm{m}$-thick) were prepared as described previously (Bianchi and Wong, 1995) and placed on the nylon mesh in an interface recording chamber (Fine Science Tools, Vancouver, British Columbia, Canada). The control solution contained (in mM): 157 $\mathrm{Na}^{+}, 136 \mathrm{Cl}^{-}, 5 \mathrm{~K}^{+}, 1.6 \mathrm{Mg}^{2+}, 2 \mathrm{Ca}^{2+}, 26 \mathrm{HCO}_{3}^{-}$, and $11 \mathrm{D}$-glucose. Perfusion media were bubbled with $95 \% \mathrm{O}_{2} / 5 \% \mathrm{CO}_{2}$ to maintain the $\mathrm{pH}$ near 7.4, and the temperature was maintained at $34-36^{\circ} \mathrm{C}$.

Electrophysiological recording. Intracellular recordings of CA3 neurons were performed using an Axoclamp 2A amplifier (Axon Instruments, Foster City, CA). Electrodes were pulled with thin-wall glass tubings and had resistance of 30-40 M $\Omega$ when filled with K-acetate $(2 \mathrm{M})$. The electrode solution also contained $10 \mathrm{mM} \mathrm{Cs}^{+}$to reduce $\mathrm{K}^{+}$current responses. $\quad N$-(2,6-dimethylphenylcarbamoylmethyl)-triethylammonium bromide (QX-314) (10 mM) was included to suppress the Q-current in voltage-clamp experiments (Perkins and Wong, 1995; Bianchi et al., 1999) but was omitted in current-clamp studies. Voltage and current signals were digitized and stored in an Intel Pentium-based computer using a 12-bit A/d converter controlled by pClamp software (Axon Instruments). Voltage-clamp experiments were performed using the single electrode discontinuous clamp mode. The headstage output was monitored continuously on an oscilloscope, and the switching frequency $(4-6 \mathrm{kHz})$ and gain $(0.5-1.0 \mathrm{nA} / \mathrm{mV})$ were adjusted so that the decay of voltage transients was complete between switch cycles.

Pharmacological agents. To optimize the conditions for studying the mGluR-mediated inward current, 6-cyano-7-nitroquinoxaline-2,3-dione (CNQX) (20 $\mu \mathrm{M})$ and 3-((R,S)-2-carboxypiperazin-4-yl)-propyl-1phosphonic acid (CPP) $(20 \mu \mathrm{M})$ were added to the perfusing solution. Tetrodotoxin (TTX) $(0.6 \mu \mathrm{M})$ was also added in some experiments as noted. U73122 (10 $\mu \mathrm{M})$, a broad spectrum PLC blocker, was applied in some studies. The mGluR agonist $(S)$-3,5-dihydroxyphenylglycine (DHPG) was purchased from Tocris Cookson (Ballwin, MO) and was bath-applied $(50 \mu \mathrm{M})$. All other chemicals were from Sigma (St. Louis, MO).

\section{RESULTS}

Previous data show that application of the mGluR agonist $( \pm)$ ( \pm )-1-aminocyclopentane-trans-1,3-dicarboxylic acid (ACPD) induced rhythmic firing of CA3 cells (Taylor et al., 1995; their Figs. $6,7)$. We now observe that DHPG, a group I agonist, produced the same response pattern (see Fig. 5Ab). At the cellular level, DHPG also elicits a voltage-dependent inward current $\left[I_{\text {mGluR(V) }}\right]$ (Chuang et al. 2000).

\section{Threshold of activation of $I_{\text {mGluR(V) }}$}

To examine the threshold of activation of $I_{\text {mGluR(V) }}$, we performed voltage-clamp experiments and measured the peak currents activated at different levels of depolarization and the peak tail currents accompanying the termination of different levels of depolarization.

Experiments were performed in the presence of TTX (control condition). Cesium was present $(10 \mathrm{~mm})$ in the intracellular recording solution to minimize the contribution of $\mathrm{K}^{+}$conductances. Control records were subtracted from those obtained in the presence of DHPG to isolate the group I mGluR responses.

Figure $1 A a$ shows that in control conditions, depolarizing command pulses from a holding potential of $-45 \mathrm{mV}$ elicited an initial outward transient current lasting $<300 \mathrm{msec}$, followed by a maintained steady outward current. After exposure to DHPG (50 $\mu \mathrm{M})$, an inward slant in the steady-state outward current developed (Fig. 1 Aa, DHPG). Subtraction of control current records from those obtained in DHPG (Fig. 1 $A b$ ) isolated the current elicited by DHPG $\left[I_{\mathrm{mGluR}(\mathrm{V})}\right]$. $I_{\mathrm{mGluR}(\mathrm{V})}$ first appeared when the depolarization approached $-70 \mathrm{mV}$ (Fig. $1 \mathrm{Ac}$ ). As the level of depolarization increased, larger inward current responses were elicited. Maximum $I_{\text {mGluR(V) }}$ responses occurred at about $-25 \mathrm{mV}$.

To determine the conductance activated by DHPG at different depolarizations, tail currents recorded at $-75 \mathrm{mV}$ after different levels of membrane potential were measured. Figure $1 \mathrm{Ba}$ shows the tail current responses that were obtained before and after exposure to DHPG. Net changes in the tail current response were obtained by subtraction of the control responses from the responses obtained in DHPG (Fig. $1 B b$ ). The data show that inward tail currents appeared after membrane potentials more depolarized than $-70 \mathrm{mV}$ (Fig. $1 \mathrm{Bc}$ ). The maximum tail current was elicited at about $-30 \mathrm{mV}$.

Thus, an inward current $\left[I_{\mathrm{mGluR}(\mathrm{V})}\right]$ was activated on stimulation of the group I mGluRs by an agonist, but the current was not expressed at membrane potentials below $-70 \mathrm{mV} . I_{\mathrm{mGluR}(\mathrm{V})}$ only appeared when the membrane potential was more depolarized than $-70 \mathrm{mV}$. At depolarizations above threshold, the amplitude of $I_{\mathrm{mGluR}(\mathrm{V})}$ increased with depolarization.

\section{$I_{\text {mGluR(v) }}$ as the pacemaker current for the bursting of single pyramidal cells}

Using current-clamp recordings, we examined the effects of DHPG on the resting potential of single CA3 neurons in the presence of TTX to suppress spiking activities. Under control condition, depolarization of the cell by current pulse injection through the recording electrode produced a step depolarization (Fig. 2Aa, Control). In the presence of DHPG, depolarization of the cell via current pulse injection to above $-70 \mathrm{mV}$ produced a step depolarization followed by a continuous, more gradual depolarization (Fig. $2 A a, D H P G$ ). This gradual depolarization was probably sustained by $I_{\text {mGluR(V) }}$ because it was elicited in the presence of DHPG and appeared only when the membrane potential was depolarized to levels above the threshold of activation of $I_{\mathrm{mGluR}(\mathrm{V})}$.

DHPG also depolarized the resting potential of hippocampal CA3 cells. In the presence of DHPG, hyperpolarizing current pulses applied at the resting potential elicited an initial fast hyperpolarization followed by a more gradual hyperpolarizing response (Fig. $2 A b, D H P G$ ). The slower hyperpolarization probably reflects the turn off of $I_{\mathrm{mGluR}(\mathrm{V})}$ because this response was absent in the control condition (Fig. 2 $\mathrm{Ab}$, Control) and was not elicited when hyperpolarizing pulses were applied at membrane potentials more hyperpolarized than $-70 \mathrm{mV}$ (data not shown).

The effects of $I_{\mathrm{mGluR}(\mathrm{V})}$ on the firing pattern of single pyramidal cells were studied in the absence of TTX and in the presence of CNQX and CPP (20 $\mu \mathrm{m}$ each) to suppress fast excitatory synaptic transmission. Picrotoxin $(50 \mu \mathrm{M})$ was also added to suppress $\mathrm{GABA}_{\mathrm{A}}$ receptor-mediated inhibition. At membrane potentials hyperpolarized to $-75 \mathrm{mV}$, cells were quiet, and no spontaneous action potentials were observed. Depolarizing cells to levels above $-70 \mathrm{mV}$ produced the gradual depolarization as noted above (Fig. 2Aa, DHPG, C). In the absence of TTX, the gradual depolarization brought the cells to threshold for action potentials. At an appropriate time during the firing activity, a short duration hyperpolarizing pulse can abruptly hyperpolarize the membrane potential to below action potential threshold (Fig. $2 C)$. After this hyperpolarization, gradual depolarization can again develop, leading to another phase of firing (Fig. 2C), and 
A

a

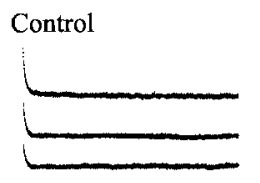

$-$
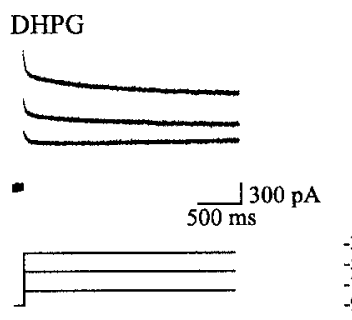

b

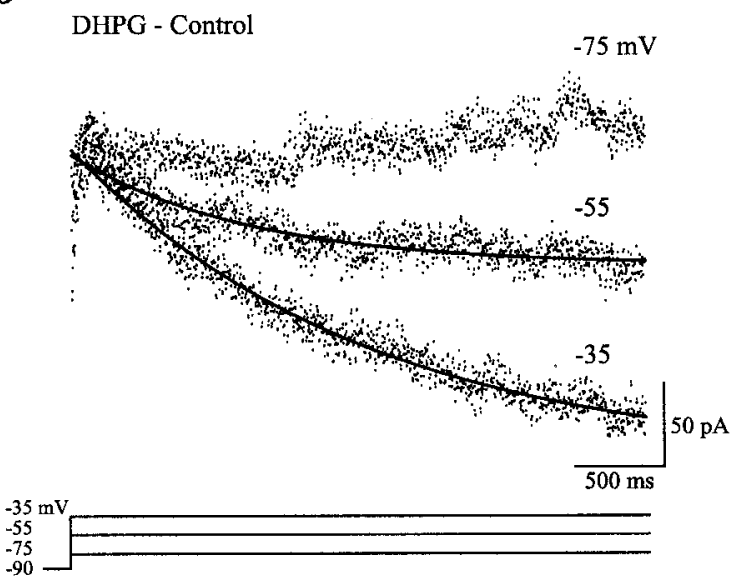

c

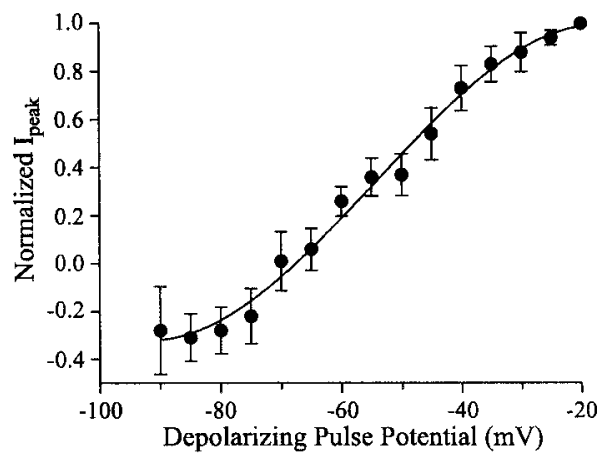

c

b
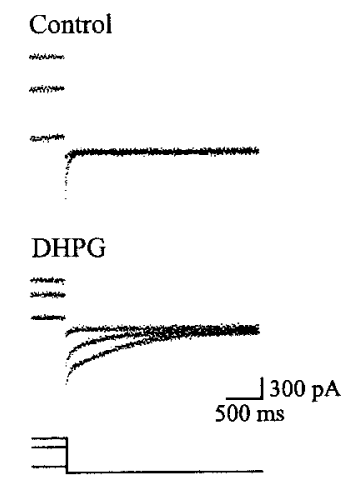
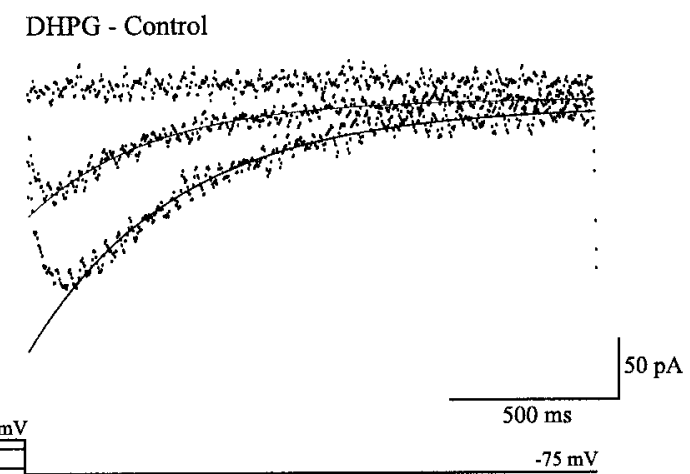

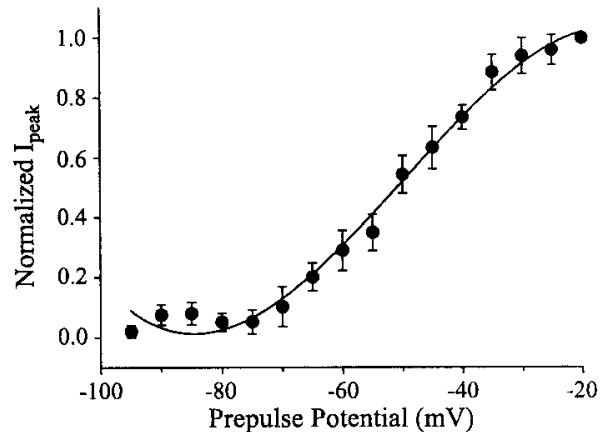

Figure 1. Properties of $I_{\mathrm{mGluR}(\mathrm{V})}$. A, Activation of $I_{\mathrm{mGluR}(\mathrm{V})} \cdot$ Aa, Current responses (top traces) to depolarizing command pulses (bottom traces) in a cell before (Control) and after (DHPG) the addition of the group I mGluR agonist DHPG (50 $\mu \mathrm{M})$. Voltage levels are the same as indicated in $A b$. $A b$, Net inward current $\left[I_{\mathrm{mGluR}(\mathrm{V})}\right]$ evoked by depolarization to indicated levels obtained by subtracting the control current traces from the corresponding ones in DHPG. $A c$, Plot of the normalized peak amplitude of $I_{\text {mGluR(v) }}$ elicited at different voltages (mean \pm SEM; data obtained from 5 cells). $B$, Deactivation of $I_{\mathrm{mGluR}(\mathrm{V})}$ after a prolonged depolarization. Ba, Current responses (top traces) after a prepulse to different voltages (bottom traces) for 2 sec. Responses obtained from the same cell in $A$. Voltage levels are the same as indicated in $B b$. Bb, Responses obtained before DHPG (Control) were subtracted from the corresponding ones after DHPG $(D H P G)$ to provide the deactivation time course of $I_{\mathrm{mGluR}(\mathrm{V})}$. Bc, Plot of normalized peak $I_{\mathrm{mGluR}(\mathrm{V})}$ after different levels of prepulse potential from four cells. Recording electrodes contained QX-314.

the event can become cyclical. In contrast, no cyclic bursting was observed in control conditions (Fig. 2B). Intracellular depolarization above firing threshold induced continuous discharge of action potentials (Fig. 2B).

Figure $2 D$ shows the pattern of cyclic bursting that was generated in the same cell, as shown in Fig. 2C, exposed to DHPG but without the imposition of the periodic hyperpolarizing pulses (as was done in the data shown in Fig. $2 C$ ). The firing phases were prolonged, and the silent intervals between them were characterized by pacemaker depolarizations. This type of cyclic bursting activity typically occurred in hippocampal CA3 cells when the membrane potential was set within the narrow range of -70 to $-67 \mathrm{mV}$.

\section{Stimulation of group I mGluRs also reduced the membrane conductance of pyramidal cells}

$I_{\text {mGluR(V) }}$ does not show inactivation and is thus persistently turned on at depolarized membrane potentials. In voltage-clamp studies at a holding potential of $-45 \mathrm{mV}$, a level that is above
$I_{\text {mGluR(V) }}$ threshold, hyperpolarizing pulses turned off $I_{\text {mGluR(V) }}$ causing the appearance of an outward current (Fig. $3 A$ ) (cf. Chuang et al. 2000). $I_{\mathrm{mGluR}(\mathrm{V})}$ should be completely turned off by hyperpolarizing pulses of sufficient amplitude [so that the membrane potential is hyperpolarized to the threshold for $\left.I_{\mathrm{mGluR}(\mathrm{V})}\right]$ and duration [so that $I_{\mathrm{mGluR}(\mathrm{V})}$ can completely deactivate]. If $I_{\mathrm{mGluR}(\mathrm{V})}$ were the only response elicited by DHPG, then the conductance of the neuron should be similar to that in control when $I_{\mathrm{mGluR}(\mathrm{V})}$ is turned off. Figure $3 B$ shows that the conductance of the cell (which should be proportional to the amplitude of the instantaneous current, $I_{2}$ ) at the end of a hyperpolarizing pulse that turned off $I_{\mathrm{mGluR}(\mathrm{V})}$ is smaller than that measured under control (indicated by $I_{1}$ ). This comparison is valid only if the ionic reversal potentials remain constant under the two measuring conditions. A plot of the amplitude of the instantaneous currents at the end of various hyperpolarizations shows that the membrane conductances were consistently reduced in the presence of DHPG (Fig. 3C). Apparently group I mGluR stimulation also reduced the membrane conductance of hippocampal pyramidal cells. 


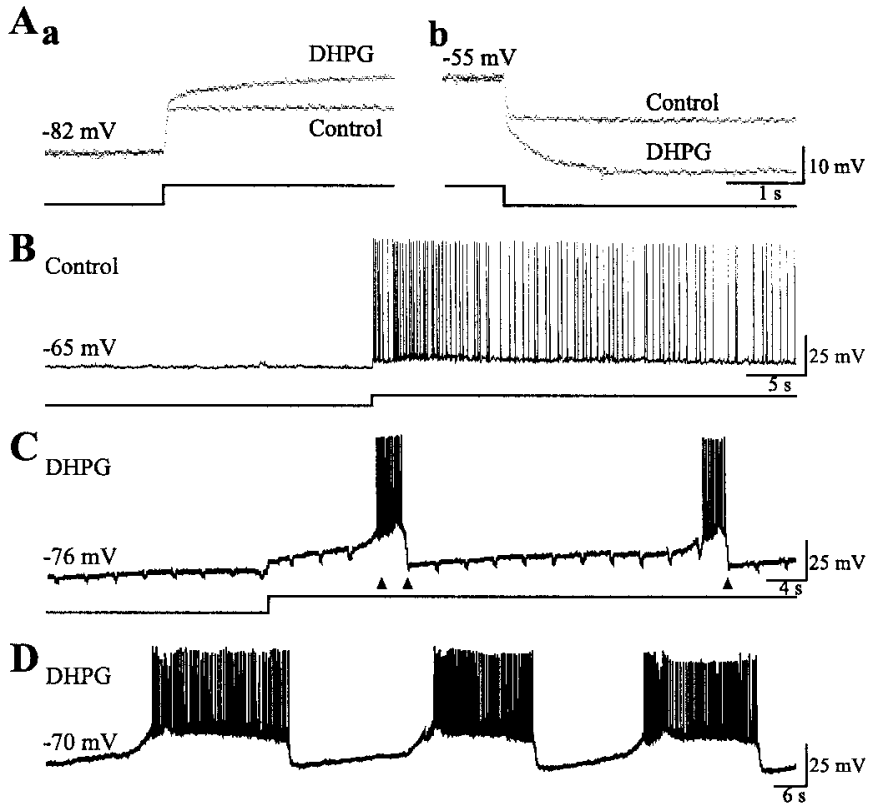

Figure 2. Effects of $I_{\mathrm{mGluR}(\mathrm{V})}$ on single cell activities. Records obtained in the presence of CNQX and CPP $(20 \mu \mathrm{M}$ each). Here and in Figure 5, recording electrodes contained $2 \mathrm{M} \mathrm{K}$-acetate without QX-314. $A a$, TTX $(0.6 \mu \mathrm{M})$ was present in the solution. Membrane voltage responses (top traces) to depolarizing current pulses (bottom traces). The voltage responses obtained before (Control) and after addition of DHPG (DHPG) in a cell are superimposed. $A b$, Hyperpolarizing responses from the same cell before and after DHPG. $B$, Responses of a CA3 cell to a prolonged depolarizing current injection in control conditions. Note that at a resting level of $-65 \mathrm{mV}$, no spontaneous depolarization develops, and above the firing threshold the cell discharges continuous action potentials. $C$, Records of spontaneous cell activities obtained in the presence of DHPG. Downward transients in the baseline of the voltage record were produced by hyperpolarizing pulses applied at regular intervals. Pulses applied during the burst did not produce obvious deflections and are indicated by arrowheads. D, Spontaneous activities recorded in the same cell as shown in $C$, without intracellular hyperpolarizing current pulses.

\section{Absence of PLC $\beta 1$-mediated signaling prevented the generation of $I_{\text {mGluR(V) }}$ but not the conductance decrease induced by group I mGluR activation}

The effects of group I mGluR stimulation were examined in CA3 neurons of PLC $\beta 1-/-$ mice under voltage clamp. Addition of DHPG produced a depolarization of $5 \pm 0.8 \mathrm{mV}(n=9)$ but did not cause noticeable change in the action potential pattern of these cells. In voltage-clamp recordings, neurons from PLC $\beta 1$ $-/-$ mice showed responses different from those obtained in wild-type mice. Addition of DHPG still caused an inward shift in the holding current; however, the outward relaxation observed in the wild-type $(\mathrm{PLC} \beta 1+/+)$ mice elicited by hyperpolarizing voltage-clamp steps (e.g., Fig. $3 A, C$ ) was no longer observed (Fig. $4 A, D H P G)$. The current-voltage $(I-V)$ relationship of the cell was linear in both the control and DHPG conditions, and the lines intercepted at approximately $-115 \mathrm{mV}$ (Fig. $4 B$ ).

Suppression of PLC signaling using U72133, a broad spectrum PLC blocker, produced similar results. DHPG produced an inward shift in the holding current and a conductance decrease. Figure 5, $C$ and $D$, summarizes the results obtained from the PLC $\beta 1-/-$ mice and wild-type mice treated with U72133, respectively. The current amplitudes for the $I-V$ relationships were measured at the end of hyperpolarizing pulses. The interception points under the two conditions were $-106.8 \pm 1.8 \mathrm{mV}$ for cells derived from mutant mice $(n=5)($ Fig. $4 C)$ and $-102.3 \pm 2.3 \mathrm{mV}$ for cells exposed to U73122 ( $n=3)$ (Fig. $4 D)$.

\section{Absence of PLC $\beta 1$-mediated signaling prevented the generation of group I mGluR-mediated synchronized activities}

Addition of DHPG elicited rhythmic episodes of epileptiform discharges in hippocampal slices that were obtained from wildtype mice (Fig. 5A) (cf. Taylor et al., 1995). The epileptiform discharges occurred in the form of synchronized oscillatory discharges of the hippocampal neurons at 15-27 Hz. Each episode of the epileptiform discharges lasted from 5 to $15 \mathrm{sec}$. The interval between episodes of oscillation lasted between 3 and $10 \mathrm{sec}$.

The rhythmic epileptiform discharges continued undeterred when the membrane potentials were set to levels below firing threshold (Fig. 5Ab, bottom trace). When cells were sufficiently depolarized, firing was prevented (depolarization block), and the oscillatory depolarizations underlying the firing were revealed. The data show that the patterns of oscillations were not significantly affected by changes in membrane potential as would be expected if the oscillations represent population events (Fig. $5 A b$ ). The involvement of a population of neurons has also been confirmed using extracellular field potential and dual intracellular recordings (Taylor et al., 1995; their Figs. 4, 5).

DHPG added to slices prepared from PLC $\beta 1-/-$ mice did not evoke obvious population responses (Fig. $5 B$ ). When cells were hyperpolarized to levels below $-75 \mathrm{mV}$, they were quiet, and on depolarization they fired continuous single action potentials with no obvious rhythmic groupings (Fig. 5Bb).

\section{DISCUSSION}

Stimulation of group I mGluRs modulates a large number of intrinsic conductances in the hippocampal neurons (for review, see Conn and Pin, 1997; Anwyl, 1999). Our results reveal that at membrane potentials subthreshold to most intrinsic depolarization-activated persistent conductances (about -70 $\mathrm{mV}$ ), group I mGluR agonists produced two major effects in hippocampal CA3 pyramidal cells: the generation of a voltagedependent inward current and the suppression of a background current most probably carried by $\mathrm{K}^{+}$.

\section{Involvement of PLC $\beta 1$ in the group I mGluR-mediated effects}

Stimulation of group I mGluRs suppressed a number of $\mathrm{K}^{+}$ conductances in hippocampal cells including the spike afterhyperpolarization (Desai and Conn, 1991; Miles and Poncer, 1993; Heuss et al., 1999), the $\mathrm{Ca}^{2+}$-dependent $\mathrm{K}^{+}$conductance (Charpak et al., 1990), a slowly inactivating voltage-dependent conductance (underlying $I_{\mathrm{D}}$ ) (Wu and Barish, 1999), a slowly inactivating $\mathrm{K}^{+}$conductance distinct from that for $I_{\mathrm{D}}$ (Lüthi et al., 1996), and the background $\mathrm{K}^{+}$conductance (Guérineau et al., 1994; Davies et al., 1995; Gereau and Conn, 1995; Bianchi et al., 1999; Chuang et al., 2000). G protein activation has been suggested to be involved in the conductance block in all cases. However, it is unclear whether transduction steps downstream from $G$ protein activation were necessary. A direct involvement of activated $G$ protein in the block of the background $\mathrm{K}^{+}$conductance is speculated because the block persisted in patch-clamp recording conditions that presumably washed out diffusible cytosolic second messengers (Guérineau et al., 1994; Lüthi et al., 1997). Our results support this suggestion because we found that the suppression of the background $\mathrm{K}^{+}$conductance by DHPG persisted in 
A

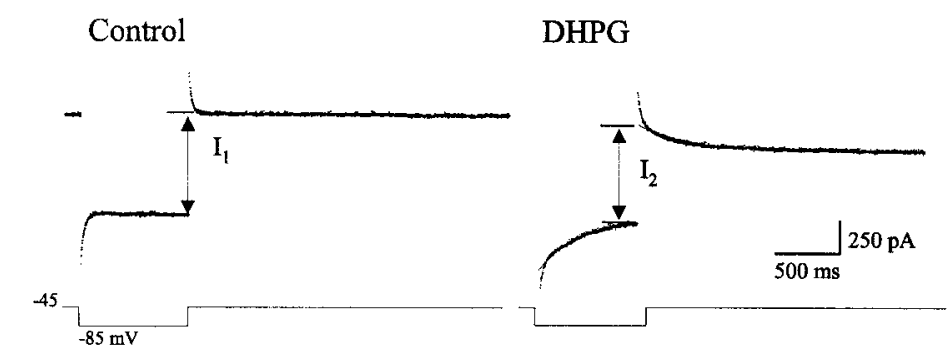

C

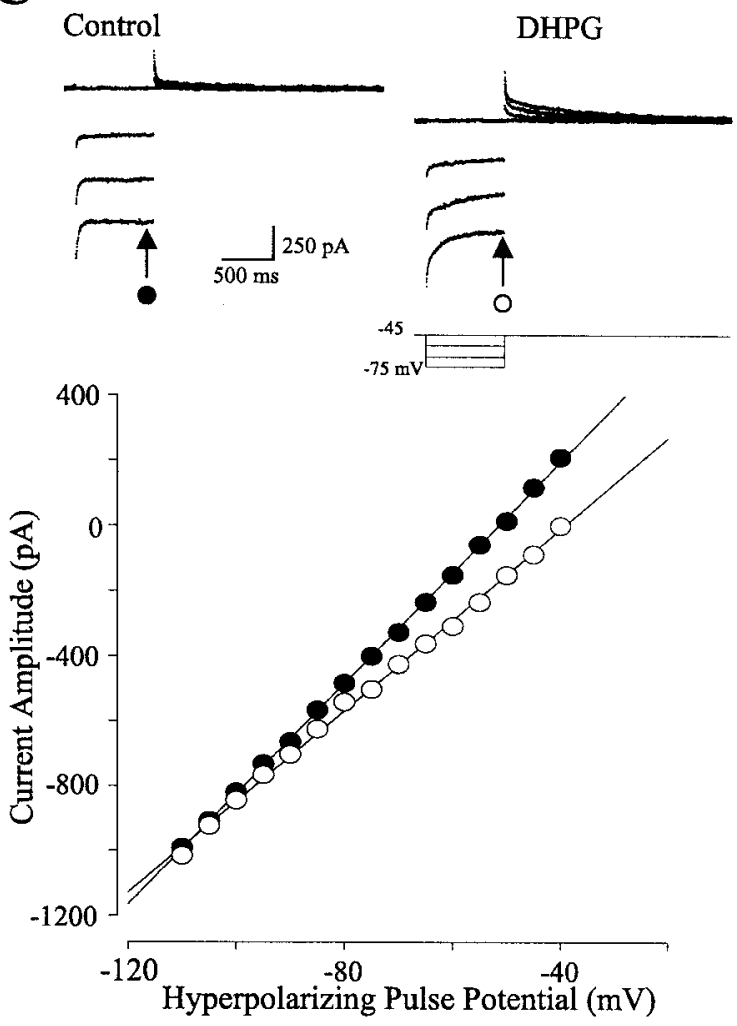

Figure 3. Estimation of the membrane conductance at the end of a hyperpolarizing pulse. A, Voltage-clamp records of the current responses (top traces) to a hyperpolarizing pulse (bottom traces) before (Control) and after (DHPG) the addition of DHPG (50 $\mu \mathrm{M}$ ). In the presence of DHPG, note the development of an outward current during the hyperpolarizing pulse and of an inward current after the hyperpolarizing pulse. $I_{1}$ and $I_{2}$ indicate the instantaneous currents recorded at the end of the hyperpolarizing pulse. $B$, The current responses in $A$ are superimposed. Segments of the responses at the termination and after the hyperpolarizing pulse are shown. The length of the segment is indicated in the voltage protocol by the two arrowheads (inset). For measurement of the instantaneous current, the flat baseline is extended back to the termination of the hyperpolarizing pulse in control ( $I_{1}$, top current trace). For $I_{2}$, the current response after the hyperpolarization was fitted with a single exponential, and the fitted curve was extrapolated to the instant when the hyperpolarization was turned off. $C$, Top, Voltage-clamp records obtained in control conditions $(C o n t r o l)$ and after addition of DHPG (DHPG). Bottom, Plot of the amplitude of the instantaneous currents measured at the end of pulses to different levels of hyperpolarization versus the level of hyperpolarization in control conditions (closed circles) and in the presence of DHPG (open circles).

the absence of PLC $\beta 1$ protein and after PLC action was blocked by U73122.

In addition to group I mGluRs, a number of other neurotransmitters coupled to the $\mathrm{G} \alpha_{\mathrm{q} / 11}$ family of $\mathrm{G}$ protein also suppress the background $\mathrm{K}^{+}$conductance of neurons in different parts of the CNS (McCormick, 1992; Pan et al., 1994; Haj-Dahmane and Andrade, 1996; Li and Guyenet, 1996; Talley et al., 2000). A family of two-pore domain $\mathrm{K}^{+}$channels (TASK) is likely to be the molecular substrate for the background $\mathrm{K}^{+}$conductance across neuronal types (Duprat et al., 1997; Leonoudakis et al., 1998) (for review, see North, 2000). It is interesting to note that in cerebellar granule cells, inhibition of background $\mathrm{K}^{+}$current by muscarinic receptor (M3) activation was not affected by agents (including U73122) that blocked transduction steps downstream from $\mathrm{G}$ protein activation (Boyd et al., 2000). Similar to our finding, these results suggest that the inhibition of the background conductance could result from a direct action of $\mathrm{G}$ protein subunits. Although the mechanism of the $\mathrm{G}$ protein subunit involved in the blockade of the background $\mathrm{K}^{+}$channels remains unknown, there is ample evidence suggesting that an opening of the inward rectifying $\mathrm{K}^{+}$channels after metabotropic receptor activation is via a direct action of the $\mathrm{G}_{\beta \gamma}$ subunit (for review, see Yamada et al., 1998).
$I_{\text {mGluR(V) }}$ can be compared with the $\mathrm{G}$ protein-independent inward current turned by group I mGluR stimulation (Heuss et al., 1999). Both showed a region of negative slope conductance in a range of negative membrane voltages. Reversal potential for $I_{\text {mGluR(V) }}$ is about $-10 \mathrm{mV}$ (Chuang et al., 2000), comparable with $-9 \mathrm{mV}$ for the $\mathrm{G}$ protein-independent current (elicited by DHPG). However there may be a difference in the transduction mechanism. Heuss et al. (1999) reported that the group I mGluRdependent current is elicited via tyrosine kinase activation. Blocking $G$ protein function did not affect its generation. The simplest explanation for our finding that PLC $\beta 1$ is required for $I_{\text {mGluR(V) }}$ generation is that the $\mathrm{G} \alpha_{\mathrm{q} / 11}$ subunit $\rightarrow$ PLC $\beta$ pathway is involved. Thus, $I_{\mathrm{mGluR}(\mathrm{V})}$ may be distinguished from the $\mathrm{G}$ protein-independent inward current. However, it remains possible that there is an as yet unknown pathway that directly links protein tyrosine phosphorylation to the activation of PLC $\beta 1$. Additional studies are required to explore this issue.

The highest level of PLC isoform in the hippocampus is PLC $\beta 1$, although PLC $\beta 3$ is also present (Tanaka and Kondo, 1994; Kim et al., 1997). The $\mathrm{G} \alpha_{\mathrm{q} / 11}$ family of $\mathrm{G}$ protein is coupled to multiple isoforms of PLC $\beta$ (Rebecchi and Pentyala, 2000). Our data suggest that induction of $I_{\mathrm{mGluR}(\mathrm{V})}$ is exclusively conveyed 

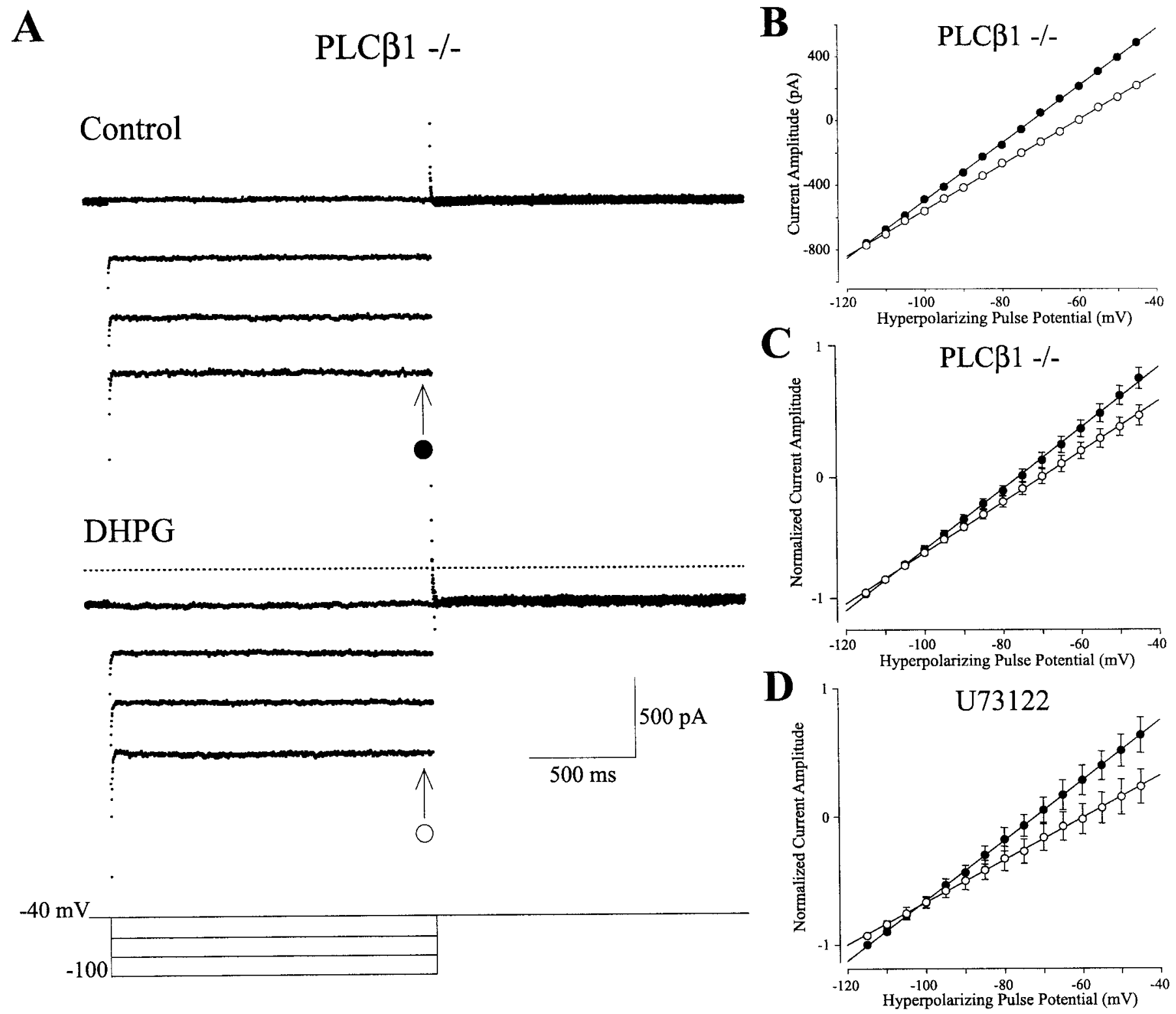

Figure 4. Voltage-clamp responses from hippocampal cells in the absence of PLC $\beta 1$-mediated signaling. $A$, Responses to hyperpolarizing pulses obtained before (Control) and after (DHPG) the addition of DHPG $(50 \mu \mathrm{M})$ in a CA3 cell obtained from a PLC $\beta 1$ knock-out mouse. $B, I-V$ plot of the instantaneous current generated by the turning off of the hyperpolarization under control (closed circles) and DHPG (open circles) conditions for the cell shown in $A$. $C$, Summary $I-V$ plot obtained from neurons of PLC $\beta 1$ knock-out mice ( $P L C \beta 1-/-; n=5$ neurons from 5 animals). $D$, Summary $I-V$ plot obtained from neurons of wild-type mice treated with the PLC blocker U73122 (10 $\mu \mathrm{M} ; n=3$ neurons from 3 animals). In $C$ and $D$, circles and the error bars indicate average responses \pm SEM, respectively, of the cells before addition of DHPG (closed circles) and after addition of DHPG (open circles).

via PLC $\beta 1$ and that PLC $\beta 3$ cannot compensate for its deficiency. The unique function of PLC $\beta 1$ is also suggested in behavioral studies in which cognitive impairment in the aged rats was shown to be correlated with a decrease in PLC $\beta 1$ isoform in the hippocampus (Nicolle et al., 1999)

Our results do not make clear which signaling steps beyond PLC $\beta 1$ are involved in the generation of $I_{\mathrm{mGluR}(\mathrm{V})}$. Data suggest that blockers of protein kinase $\mathrm{C}$ do not affect the generation of the group I mGluR-dependent synchronized discharges (Chen et al., 1998), nor did the blockers suppress $I_{\text {mGluR(v) }}$ generation (our unpublished observation). These data suggest that activation of $I_{\mathrm{mGluR}(\mathrm{V})}$ and the associated population discharges primarily engages the PLC $\rightarrow \mathrm{IP}_{3}$ branch of the transduction path.

\section{Control of single cell and population activities by $I_{\text {mGluR(V) }}$}

In the PLC $\beta 1-/-$ preparation, DHPG only elicited a decrease in conductance and did not activate $I_{\mathrm{mGluR}(\mathrm{V})}$. In the absence of $I_{\text {mGluR(V) }}$, spontaneous rhythmic firing periods in single cells were no longer observed. Furthermore, DHPG failed to induce synchronized oscillations of a population of synaptically connected CA3 cells.

Because $I_{\text {mGluR(V) }}$ has a low threshold, the current depolarized resting pyramidal cells to a level between -45 and $-40 \mathrm{mV}$. The membrane potential was maintained at this level because $I_{\text {mGluR(V) }}$ is noninactivating. Hyperpolarizing pulses deacti- 
A $\quad$ B

a Wild-Type

Control

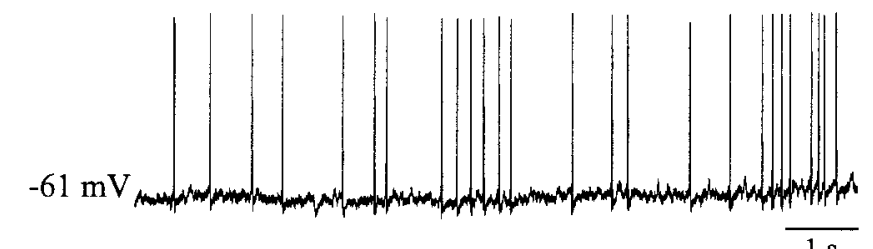

b

DHPG

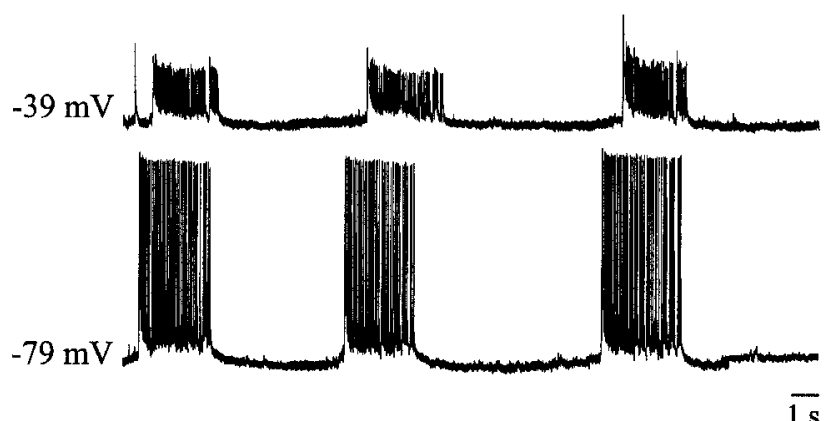

a

\section{Control}

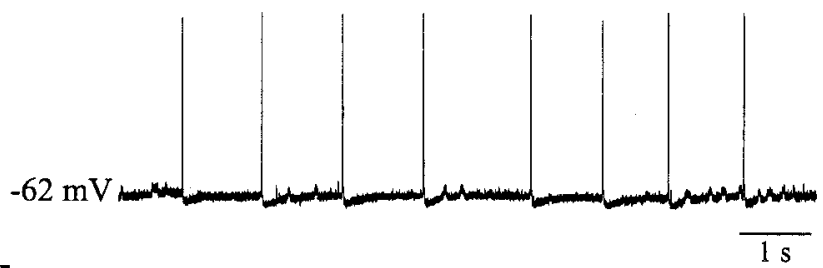

b

DHPG

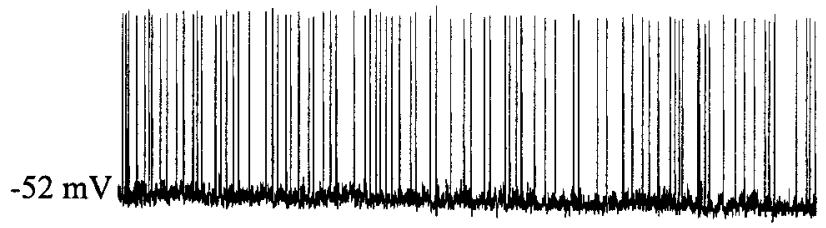

$-81 \mathrm{mV}$.

Figure 5. Effects of the group I mGluR agonist DHPG on hippocampal population activities. $A$, Spontaneous activities recorded before $(C o n t r o l)$ and after $(D H P G)$ the addition of DHPG $(50 \mu \mathrm{M})$ in the same cell obtained from a wild-type mouse. Top and bottom traces in $A b$ are records obtained at different times and at different membrane potentials. Note that action potentials are triggered few millivolts depolarized to the holding potentials, suggesting an ectopic site of generation. B, Recordings obtained before (Control) and after DHPG (DHPG) from a hippocampal neuron of a PLC $\beta 1$ knock-out mouse $(P L C \beta 1-/-)$. Bb, The top and bottom records are traces obtained from the same cell at different membrane potentials.

vate $I_{\mathrm{mGluR}(\mathrm{V})}$ and, when sufficiently large, repolarize the cell by deactivating $I_{\text {mGluR(V) }}$ (Fig. $2 A b$ ).

The depolarization sustained by $I_{\text {mGluR(V) }}$ drives the cell to firing threshold (Fig. 2C,D). The period of firing has a finite duration and is terminated by a rapid repolarization. Presumably, during the continuous firing, outward current is cumulatively activated. The outward current eventually exceeds the amplitude of $I_{\mathrm{mGluR}(\mathrm{V})}$, and repolarization ensues. A likely candidate for the outward current is the remainder of $\mathrm{Ca}^{2+}$-dependent $\mathrm{K}^{+}$current that escaped a blockade by DHPG. The hypothesis that outward current did build up during firing is supported by the observation that short hyperpolarizing pulses that were applied during the early part of a firing cycle did not cause repolarization, whereas the same pulses when applied later in the cycle terminated the firing (e.g., Fig. 2C).

Stimulation of group I mGluRs modulates a number of other intrinsic ionic channels such as the voltage-dependent $\mathrm{Ca}^{2+}$ channels and $\mathrm{Ca}^{2+}$-activated $\mathrm{K}^{+}$channels (for review, see Conn and Pin, 1997; Anwyl, 1999; Wong et al., 1999). Thus, although $I_{\text {mGluR(V) }}$ may play a unique role in serving as the pacemaker for the rhythmic burst firing as well as in maintaining the depolarization underlying the firing phase (because of its low threshold and noninactivating properties, respectively), effects of group I mGluR activation on other intrinsic currents may contribute to shaping the firing rate and pattern within the burst.

Cycles of $I_{\text {mGluR(V)- }}$-generated firing in single cells could provide the basic pattern for the cycles of synchronized epileptiform discharges that are observed after group I mGluR stimulation in the synaptically intact CA3 population. Synchronization of the firing activities in the population depends on the function of recurrent synapses because the synchronized discharges disappeared when ionotropic glutamate receptor (iGluR) antagonists were added to block the recurrent synapses.

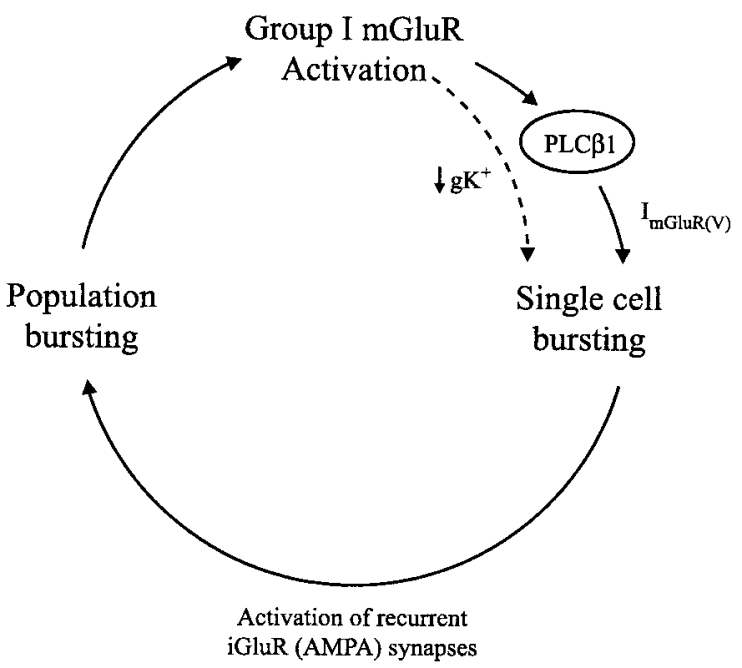

Figure 6. Summary of the proposed mechanism of generation of synchronized population discharges after the stimulation of group I mGluRs. The dashed line indicates a speculated involvement of the decrease in $\mathrm{K}^{+}$ conductance to single cell bursting (see Discussion for details). 
Figure 6 summarizes the steps leading to the generation of group I mGluR-dependent synchronized discharges in hippocampal slices. Group I mGluR activation through PLC $\beta 1$ transduction elicits $I_{\mathrm{mGluR}(\mathrm{V})} . I_{\mathrm{mGluR}(\mathrm{V})}$ generates the pacemaker potential and the sustained depolarization for single cell cyclic bursting. Action potentials in single cells become synchronized via an activation of the recurrent synapses. Previous data show that blockade of NMDA receptors (Taylor et al., 1995; Galoyan and Merlin, 2000) and suppression of GABAergic inhibition (mediated by both $\mathrm{GABA}_{\mathrm{A}}$ and $\mathrm{GABA}_{\mathrm{B}}$ receptors) (Taylor et al., 1995; see also Merlin and Wong, 1997) did not affect the pattern of the group I mGluR-induced population discharges. Thus, the recurrent synaptic excitation underlying the synchronization may only involve the AMPA receptors. Simulation studies on the mechanisms of rhythmic population oscillations have emphasized the necessary role of tonic depolarization and recurrent synapses (Traub et al., 1992). Our data are consistent with such a hypothesis and introduce $I_{\operatorname{mGluR}(\mathrm{V})}$ as a candidate for initiating and sustaining the tonic depolarization.

Once the group I mGluR agonist has induced the synchronized bursting, the synaptically released glutamate during the discharge can begin to activate subsynaptic group I mGluRs and maintain the synchronized discharges in the absence of an exogenously applied agonist (Merlin and Wong, 1997; Merlin et al., 1998; Merlin, 1999). At present, the conditions for the synaptic induction of the group I mGluR-mediated discharges have not been examined in detail. Group I mGluRs may be recruited when glutamatergic synapses are strongly activated, such as during ictal-like discharges elicited by 4-aminopyridine (Arvanov et al., 1995). In vivo kindling also elicits excessive glutamate release (Meldrum, 1994). It is possible that group I mGluRs are activated in this condition and contribute to epileptogenesis.

\section{REFERENCES}

Anwyl R (1999) Metabotropic glutamate receptors: electrophysiological properties and role in plasticity. Brain Res Rev 29:83-120.

Arvanov VL, Holmes KH, Keele NB, Shinnick-Gallagher P (1995) The functional role of metabotropic glutamate receptors in epileptiform activity induced by 4-aminopyridine in the rat amygdala slice. Brain Res 669:140-144.

Bianchi R, Wong RKS (1995) Excitatory synaptic potentials dependent on metabotropic glutamate receptor activation in guinea-pig hippocampal pyramidal cells. J Physiol (Lond) 487:663-676.

Bianchi R, Young SR, Wong RKS (1999) Group I mGluR activation causes voltage-dependent and -independent $\mathrm{Ca}^{2+}$ rises in hippocampal pyramidal cells. J Neurophysiol 81:2903-2913.

Boyd DF, Millar JA, Watkins CS, Mathie A (2000) The role of $\mathrm{Ca}^{2+}$ stores in the muscarinic inhibition of $\mathrm{K}^{+}$current $\mathrm{I}_{\mathrm{K}(\mathrm{SO})}$ in neonatal rat cerebellar granule cells. J Physiol (Lond) 529:321-331.

Charpak S, Gähwiler BH, Do KQ, Knöpfel T (1990) Potassium conductances in hippocampal neurons blocked by excitatory amino acid transmitters. Nature 347:765-767.

Chen X, Bianchi R, Wong RKS (1998) Involvement of protein kinase C in mGluR-mediated oscillatory activity in the guinea pig hippocampus. Soc Neurosci Abstr 24:1088.

Chuang SC, Bianchi R, Wong RKS (2000) Group I mGluR activation turns on a voltage-dependent inward current in hippocampal pyramidal cells. J Neurophysiol 83:2844-2853.

Congar P, Leinekugel X, Ben-Ari Y, Crepel V (1997) A long-lasting calcium-activated nonselective cationic current is generated by synaptic stimulation or exogenous activation of group I metabotropic glutamate receptors in CA1 pyramidal neurons. J Neurosci 17:5366-5379.

Conn RJ, Pin JP (1997) Pharmacology and functions of metabotropic glutamate receptors. Annu Rev Pharmacol Toxicol 37:205-237.

Davies CH, Clarke VR, Jane DE, Collingridge GL (1995) Pharmacology of postsynaptic metabotropic glutamate receptors in rat hippocampal CA1 pyramidal neurones. Br J Pharmacol 116:1859-1869.

Desai MA, Conn PJ (1991) Excitatory effects of ACPD receptor activation in the hippocampus are mediated by direct effects on pyramidal cells and blockade of synaptic inhibition. J Neurophysiol 66:40-52.

Duprat F, Lesage F, Fink M, Reyes R, Heurteaux C, Lazdunski M (1997)
TASK, a human background $\mathrm{K}^{+}$channel to sense external $\mathrm{pH}$ variations near physiological pH. EMBO J 16:5464-5471.

Galoyan SM, Merlin LR (2000) Long-lasting potentiation of epileptiform bursts by group I mGluRs is NMDA receptor independent. J Neurophysiol 83:2463-2467.

Gereau 4th RW, Conn PJ (1995) Roles of specific metabotropic glutamate receptor subtypes in regulation of hippocampal CA1 pyramidal cell excitability. J Neurophysiol 74:122-129.

Guérineau NC, Gähwiler BH, Gerber U (1994) Reduction of resting K ${ }^{+}$ current by metabotropic glutamate and muscarinic receptors in rat CA3 cells: mediation by G-proteins. J Physiol (Lond) 474:27-33.

Haj-Dahmane S, Andrade R (1996) Muscarinic activation of a voltagedependent cation nonselective current in rat association cortex. J Neurosci 16:3848-3861.

Heuss C, Scanziani M, Gähwiler BH, Gerber U (1999) G-protein independent signaling mediated by metabotropic glutamate receptors. Nat Neurosci 2:1070-1077.

Kim D, Jun KS, Lee SB, Kang NG, Min DS, Kim YH, Ryu SH, Suh PG, Shin HS (1997) Phospholipase C isozymes selectively couple to specific neurotransmitter receptors. Nature 18:290-293.

Leonoudakis D, Gray AT, Winegar BD, Kindler CH, Harada M, Taylor DN, Chavez RA, Forsayeth JR, Yost CS (1998) An open rectifier potassium channel with two pore domains in tandem cloned from rat cerebellum. J Neurosci 18:868-877.

Li YW, Guyenet PG (1996) Angiotensin II decreases a resting $\mathrm{K}^{+}$ conductance in rat bulbospinal neurons of the $\mathrm{C} 1$ area. Circ Res 78:274-282.

Lüthi A, Gähwiler BH, Gerber U (1996) A slowly inactivating potassium current in CA3 pyramidal cells of rat hippocampus in vitro. J Neurosci 16:586-594.

Lüthi A, Gähwiler BH, Gerber U (1997) $1 S, 3 R$-ACPD induces a region of negative slope conductance in the steady-state current-voltage relationship of hippocampal pyramidal cells. J Neurophysiol 77:221-228.

McCormick DA (1992) Neurotransmitter actions in the thalamus and cerebral cortex and their role in neuromodulation of thalamocortical activity. Prog Neurobiol 39:337-388.

Meldrum BS (1994) The role of glutamate in epilepsy and other CNS disorders. Neurology 44:S14-23.

Merlin LR (1999) Group I mGluR-mediated silent induction of longlasting epileptiform discharges. J Neurophysiol 82:1078-1081.

Merlin LR, Wong RKS (1997) Role of group I mGluRs in the patterning of epileptiform activities in vitro. J Neurophysiol 78:539-544.

Merlin LR, Bergold PJ, Wong RKS (1998) Requirement of protein synthesis for group I mGluR-mediated induction of epileptiform discharges. J Neurophysiol 80:989-993.

Miles R, Poncer JC (1993) Metabotropic glutamate receptors mediate a post-tetanic excitation of guinea-pig hippocampal inhibitory neurones. J Physiol (Lond) 463:461-473.

Nicolle MM, Colombo PJ, Gallagher M, McKinney M (1999) Metabotropic glutamate receptor-mediated hippocampal phospoinositide turnover is blunted in spatial learning-impaired aged rats. J Neurosci 19:9604-9610.

North RA (2000) Potassium-channel closure taken to TASK. Trends Neurosci 23:234-235.

Pan ZZ, Grudt TJ, Williams JT (1994) $\alpha_{1}$-adrenoreceptors in rat dorsal raphe neurons: regulation of two potassium conductances. J Physio (Lond) 478:437-447.

Perkins KL, Wong RKS (1995) Intracellular QX-314 blocks the hyperpolarization-activated inward current $\mathrm{I}_{\mathrm{q}}$ in hippocampal CA1 pyramidal cells. J Neurophysiol 73:911-915.

Pozzo-Miller LD, Petrozzino JJ, Connor JA (1995) G protein-coupled receptors mediate a fast excitatory postsynaptic current in CA3 pyramidal neurons in hippocampal slices. J Neurosci 15:8320-8330.

Rebecchi MJ, Pentyala SN (2000) Structure, function and control of phospholipase C. Physiol Rev 80:1291-1335.

Talley EM, Lei Q, Sirois JE, Bayliss DA (2000) TASK-1, a two-pore domain $\mathrm{K}^{+}$channel, is modulated by multiple neurotransmitters in motoneurons. Neuron 25:399-410.

Tanaka O, Kondo H (1994) Localization of mRNAs for three novel members (beta 3 , beta 4 and gamma 2) of phospholipase $\mathrm{C}$ family in mature rat brain. Neurosci Lett 182:17-20.

Taylor GW, Merlin LR, Wong RKS (1995) Synchronized oscillations in hippocampal CA3 neurons induced by metabotropic glutamate receptor activation. J Neurosci 15:8039-8052.

Traub RD, Miles R, Buzsáki G (1992) Computer simulation of carbachol-driven rhythmic population oscillations in the CA3 region of the in vitro rat hippocampus. J Physiol (Lond) 451:653-672.

Wong RKS, Bianchi R, Taylor GW, Merlin LR (1999) Role of metabotropic glutamate receptors in epilepsy. Adv Neurol 79:685-698.

Wu R-L, Barish M (1999) Modulation of a slowly inactivating potassium current, $\mathrm{I}_{\mathrm{D}}$, by metabotropic glutamate receptor activation in cultured hippocampal pyramidal neurons. J Neurosci 19:6825-6837.

Yamada M, Inanobe A, Kurachi Y (1998) G protein regulation of potassium ion channels. Pharmacol Rev 50:723-760. 